\title{
A RESULT FOR DENTISTRY IN WEST MIDLANDS AS BDA AND LDC UNITE ON MINOR ORAL SURGERY
}

The British Dental Association (BDA) has been pleased to see NHS England Birmingham, Solihull and the Black Country rethink plans to oblige dental practitioners to provide information on the minor oral surgery services they are able to provide.

The Area Team covering Sandwell, Dudley, Wolverhampton, Walsall, Solihull, Birmingham, Hereford, Worcestershire, Coventry and Warwickshire has now withdrawn a letter it issued to general dental practitioners following concerted pressure from the BDA and Local Dental Committees (LDCs).

The BDA were concerned that some dentists (particularly younger or newly qualified dentists) might be pushed towards delivering treatment that they are not comfortable with, or risk facing a breach of contract. It asked for the withdrawal of the letter to enable LDCs to discuss this issue with the Area Team before it went to individual practitioners.

Henrik Overgaard-Nielsen, Chair of the BDA's General Dental Practice Committee said: 'This is a result for thousands of dentists across the West Midlands, and it shows what we can achieve when we work together. The BDA and LDCs spoke with one voice, and NHS England responded. And it means Birmingham dentists are not being placed in a position where they could find themselves in jeopardy, or even breach of contract through no fault of their own.

'Our profession doesn't seek confrontation. We want to see problems solved, and secure the best results for both patients and practitioners. We are seeing clear recognition from the Area Team that this kind of professional input was welcome. It's a clear lesson, that if we are to avoid future impasses it will require openness on all sides and an end to last minute announcements. This gives me hope that other areas will act in the same spirit.'

\section{CALLS FOR SMOKING BAN TO BE EXTENDED}

A smoking exclusion zone should be established around pubs, bars and schools, according to a report from the Royal Society for Public Health (RSPH).

The report is calling for public confusion over nicotine to be addressed as a way of encouraging smokers to use safer forms of the substance. This would mean extending the smoking ban to beer gardens, al fresco dining areas and parks as means to encourage people to use nicotine replacement therapy (NRT), such as e-cigarettes.

Pembrokeshire Council in Wales already have proposals backed to ban smoking in parks, sports grounds, playing fields, car parks and beaches.
Shirley Cramer CBE, Chief Executive of RSPH, said: 'Over 100,000 people die from smoking-related disease every year in the UK. While we have made good progress to reduce smoking rates, 1 in 5 of us still does.

'Getting people onto nicotine rather than using tobacco would make a big difference to the public's health - clearly there are issues in terms of having smokers addicted to nicotine, but this would move us on from having a serious and costly public health issue from smoking-related disease to instead address the issue of addiction to a substance which in and of itself is not too dissimilar to caffeine addiction.'

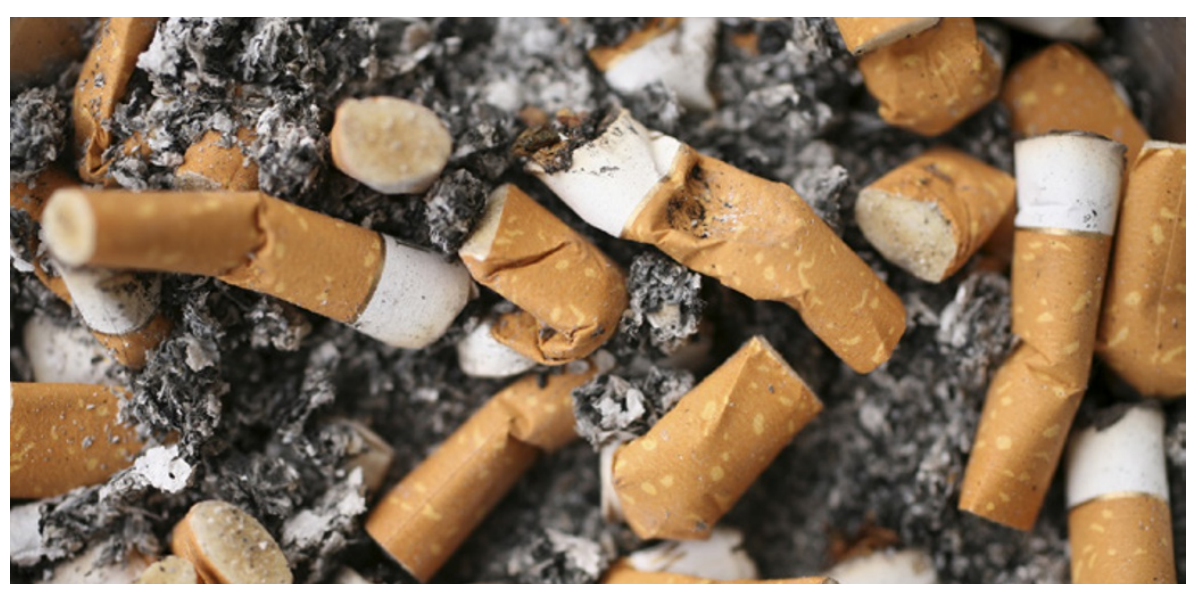

